Research Article

\title{
Self-Designed Hydrophilicity-Related Geomaterials and Their Testing Utility in Simulation of Overlying Strata Instability
}

\author{
Hao Zha $\mathbb{D}^{1}{ }^{1}$ Weiqun Liu $\mathbb{D}^{1,2,3}$ and Qinghong Liu ${ }^{2}$ \\ ${ }^{1}$ State Key Laboratory for Geomechanics \& Deep Underground Engineering, China University of Mining and Technology, \\ Xuzhou, Jiangsu 221116, China \\ ${ }^{2}$ School of Mechanics and Civil Engineering, China University of Mining and Technology, Xuzhou, Jiangsu 221116, China \\ ${ }^{3}$ College of Architecture and Civil Engineering, Wuyi University, Wuyishan 354300, China \\ Correspondence should be addressed to Weiqun Liu; wqliu@cumt.edu.cn
}

Received 14 June 2019; Accepted 30 July 2019; Published 10 October 2019

Academic Editor: Luigi Nicolais

Copyright (c) 2019 Hao Zha et al. This is an open access article distributed under the Creative Commons Attribution License, which permits unrestricted use, distribution, and reproduction in any medium, provided the original work is properly cited.

\begin{abstract}
This paper mainly involved the testing of self-designed hydrophilicity-related geomaterials and application of overlying strata monitoring in a mining area in Northwest China. We employed the orthogonal testing technique to select the ingredient ratio of hydrophilicity-related geomaterials and optimized the mechanical properties of materials, such as density, elastic modulus, Poisson ratio, compressive strength, tensile strength, and water absorption rate on the basis of regression analysis. It can be seen that the proportion of the mixture clearly determines the mechanical properties of similar materials. Among them, the content of silicone oil and the cement-Vaseline ratio have the most obvious effects on the mechanical properties of the material. By using the hydrophilicity-related geomaterials with ingredient optimization, we built a physical model to simulate the failure progress of the workface in one of the coal mines in Northwest China. It was shown that three remarkable characteristic parts, including collapse zone, fissure zone, and layer-separating space, appear in the overlying strata. Furthermore, the fractured zone above the separating band is just located under the main aquifer. Finally, compared with in-field data, it was verified that the height of the collapse zone and water-guiding fissure zone measured at three boreholes are in good agreement with the experiment. Thus, the failure mode of overburden and the vertical stress and displacement changes are consistent with the actual engineering. Self-developed hydrophilicity-related geomaterials can be applied to laboratory physical simulation experiments of overlying strata. It provides the basis for future research on large-scale physical water-containing similar simulation experiments.
\end{abstract}

\section{Introduction}

Underground problems in coal mining are difficult to be found through actual field observation. Therefore, physically experimental simulation becomes a particularly effective method to study such problems. The different ingredients of similar materials can exhibit different hydrological and mechanical properties corresponding to the rock varieties in the field. Reasonable similarity ratio plays a decisive role in the successful simulation. With the designed ratios, properties of in situ rock or soil can also be simulated more accurately, including deformation, stress, crack evolution, and structure instability.

In recent years, many scholars have developed a variety of similar materials in the fields of mining, geology, oil, natural gas, and hydraulic engineering [1-10]. In order to study the backfill materials of mines, Chen et al. [3] developed a mixture of clean river sand, fly ash, and gypsum to develop low-strength similar materials that can be used in the laboratory. However, in the process of mineral resources exploitation, there is a great demand for protecting local water resources [11]. Especially in the northwestern region of China, the fragile environment and less water resources have resulted in severe irreversible issues [12]. Therefore, in order to simulate the characteristics of rocks more accurately, the hydrophilicity of materials should be considered in the simulation. As for the hydrophilic similar materials, a new material has been developed by Wang with paraffin, sand, talc powder, and hydraulic oil, PSTO. These materials play an important role in fluid-solid coupling [13]. However, 
as a similar material, paraffin wax has complex preparation process and high temperature requirements. The preparation process has great influence on the material properties, and the preparation period is too long. Thus, to ensure that the mechanical properties of materials are not affected by water consumption and experimental time during the experiment, the development of similar materials for coal seam overburden is very important.

In addition, building similar physical models by using similar material ratios and simulating complex underground large-scale engineering problems indoors are also widely used in the field of geology [10, 14-19]. Guo et al. [20] successfully simulated the evolution of water inrush fissures and the process of water inrush in a mining area by using a similar material physical model and put forward effective preventive measures for water inrush from the floor. As generally known, overburden movement during mining has always been the key factor to study roof fracture subsidence and water inrush disaster. In this regard, Wu et al. [21] combines physical experiments with digital photogrammetry. Two similar material model tests were carried out, and the motion of the model was observed by high-precision, close-range digital photogrammetry. The law of overburden movement was successfully simulated. It also proves that it is feasible to simulate the movement of overburden structure by using the similar physical model.

In this paper, the mechanical properties and hydrophilicity of rock are considered comprehensively. Orthogonal tests with sand, barite, calcium carbonate, cement, Vaseline, and silicone oil are carried out. A series of hydrophilicity-related geomaterials satisfying geological parameters were developed. Through experimental tests, the relationship between similar proportions and material properties was fitted. On this basis, combined with the engineering geological parameters in northwestern China, a similar model was established to simulate the mechanical behavior under mining conditions by using these hydrophilicity-related geomaterials.

\section{Hydrophilicity-Related Geomaterials}

2.1. Materials and Methods. Hydrophilicity-related geomaterials were a mixture of sand, barite, calcium carbonate, cement, Vaseline, and silicone oil. Among them, sand, barite, and calcium carbonate are used as aggregates, cement and Vaseline are used as binders. Also, silicone oil acts as a hydrophilicity regulator. The main material properties make the similar materials studied more general and satisfy the requirements of similar models for various types of geotechnical engineering. To simulate the rock layer widely, similar materials with aggregate-binder ratio, cement-Vaseline ratio, barite ratio, calcium carbonate ratio, and content of silicone oil were tested in an orthogonal study that different factors affecting the dependent variable are arranged in an orthogonal list to find their optimal parameter values just by a few tests.

To investigate the effect of these factors on mechanical properties of the materials, 25 groups of samples were examined for five factors and five levels. Also, the orthogonal test scheme is shown in Table 1 . The quality of water added in the process of original material mixing is $8 \%$ of the total amount of the solid.

In order to facilitate the measurement of material properties, original materials are made into standard cylindrical specimens with dimensions of $\Phi 50 \mathrm{~mm} \times 100 \mathrm{~mm}$ and standard Brazilian disc specimens with dimensions of $\Phi 50 \mathrm{~mm} \times 100 \mathrm{~mm}$ by a self-designed mold. Also, each group includes 8 specimens. In order to avoid the effect of density on mechanical properties, wet density of all samples is set to $1936 \mathrm{~kg} / \mathrm{m}^{3}$. Therefore, the quality of the standard sample is $380 \mathrm{~g}$ and Brazil specimen is $95 \mathrm{~g}$, not only ensuring the similarity ratio of quality of similar materials and natural rock is about $1-1.5$ but also conducive to the production of molding samples. The original materials are clean river sand, barite powder, calcium carbonate, cement, Vaseline, and silicone oil (sand was screened in advance using a sieve). The original materials and production process are shown in Figure 1.

2.2. Testing Analysis of Mechanical Properties. Standard specimens were subjected to uniaxial compression and the Brazil splitting test using the electronic universal testing machine (Figure 2). Also, their compressive strength, tensile strength, elastic modulus, Poisson's ratio, density of similar materials, and water absorption rate with respective mixing ratios are given in Table 2 .

The test results show that the sample density is about 1.6397 to $1.8206 \mathrm{~g} / \mathrm{cm}^{3}$ and the Poisson's ratio is between 0.093 and 0.361 . Tensile strength with different mixing ratio ranges from 0.0194 to $0.1352 \mathrm{MPa}$, and there is a fluctuation in the number of uniaxial compressive strength from 0.265 to $2.6600 \mathrm{MPa}$. The elastic modulus is about 0.0365 to $0.6080 \mathrm{GPa}$. The water absorption rate is between $0.354 \%$ and $16.094 \%$. The mechanical properties of similar materials are very different, which can be simulated for soft rock, medium hardness, and high hardness rock mass in practical engineering.

The variations in the mechanical properties of the similar material with factors are shown in Figure 3. Spearman correlation coefficients are calculated in Table 3.

Density of the similar material is mainly affected by the content of silicone oil. We can see clearly that density decreases with an increase in the silicone oil content, and so do the barite ratio and calcium carbonate ratio. The increase in aggregates causes a slight decrease in density. Conversely, the increase in the content of Vaseline in the cement will increase the density.

Main influence factors of Poisson's ratio are the cementVaseline ratio and the barite ratio. Also, with the increase in the amount of Vaseline and barite, Poisson's ratio shows a nearly linear increase. Besides, the aggregate-binder ratio has little effect on Poisson's ratio and is probably positively correlated. There is a positive and a negative correlation between the ratio of calcium carbonate and the ratio of silicone oil, and the correlation is small.

Similar trends can be found for the strength of similar materials. The cement-Vaseline ratio and the ratio of silicone 
TABle 1: Orthogonal test scheme.

\begin{tabular}{|c|c|c|c|c|c|}
\hline Number & $\begin{array}{l}\text { Aggregate-binder ratio } \\
\text { (A) }\end{array}$ & $\begin{array}{l}\text { Cement-Vaseline ratio } \\
\text { (B) }\end{array}$ & $\begin{array}{l}\text { Barite ratio (\%) } \\
(\mathrm{C})\end{array}$ & $\begin{array}{l}\text { Calcium carbonate ratio (\%) } \\
\text { (D) }\end{array}$ & $\begin{array}{c}\text { Content of silicone oil (\%) } \\
\text { (E) }\end{array}$ \\
\hline 1 & $5: 1$ & $4: 1$ & 0 & 0 & 0 \\
\hline 2 & $5: 1$ & $3: 1$ & 10 & 10 & 3 \\
\hline 3 & $5: 1$ & $2: 1$ & 20 & 20 & 6 \\
\hline 4 & $5: 1$ & $1: 1$ & 30 & 30 & 9 \\
\hline 5 & $5: 1$ & $1: 2$ & 40 & 40 & 12 \\
\hline 6 & $6: 1$ & $4: 1$ & 10 & 20 & 9 \\
\hline 7 & $6: 1$ & $3: 1$ & 20 & 30 & 12 \\
\hline 8 & $6: 1$ & $2: 1$ & 30 & 40 & 0 \\
\hline 9 & $6: 1$ & $1: 1$ & 40 & 0 & 3 \\
\hline 10 & $6: 1$ & $1: 2$ & 0 & 10 & 6 \\
\hline 11 & $7: 1$ & $4: 1$ & 20 & 40 & 3 \\
\hline 12 & $7: 1$ & $3: 1$ & 30 & 0 & 6 \\
\hline 13 & $7: 1$ & $2: 1$ & 40 & 10 & 9 \\
\hline 14 & $7: 1$ & $1: 1$ & 0 & 20 & 12 \\
\hline 15 & $7: 1$ & $1: 2$ & 10 & 30 & 0 \\
\hline 16 & $8: 1$ & $4: 1$ & 30 & 10 & 12 \\
\hline 17 & $8: 1$ & $3: 1$ & 40 & 20 & 0 \\
\hline 18 & $8: 1$ & $2: 1$ & 0 & 30 & 3 \\
\hline 19 & $8: 1$ & $1: 1$ & 10 & 40 & 6 \\
\hline 20 & $8: 1$ & $1: 2$ & 20 & 0 & 9 \\
\hline 21 & $9: 1$ & $4: 1$ & 40 & 30 & 6 \\
\hline 22 & $9: 1$ & $3: 1$ & 0 & 40 & 9 \\
\hline 23 & $9: 1$ & $2: 1$ & 10 & 0 & 12 \\
\hline 24 & $9: 1$ & $1: 1$ & 20 & 10 & 0 \\
\hline 25 & $9: 1$ & $1: 2$ & 30 & 20 & 3 \\
\hline
\end{tabular}

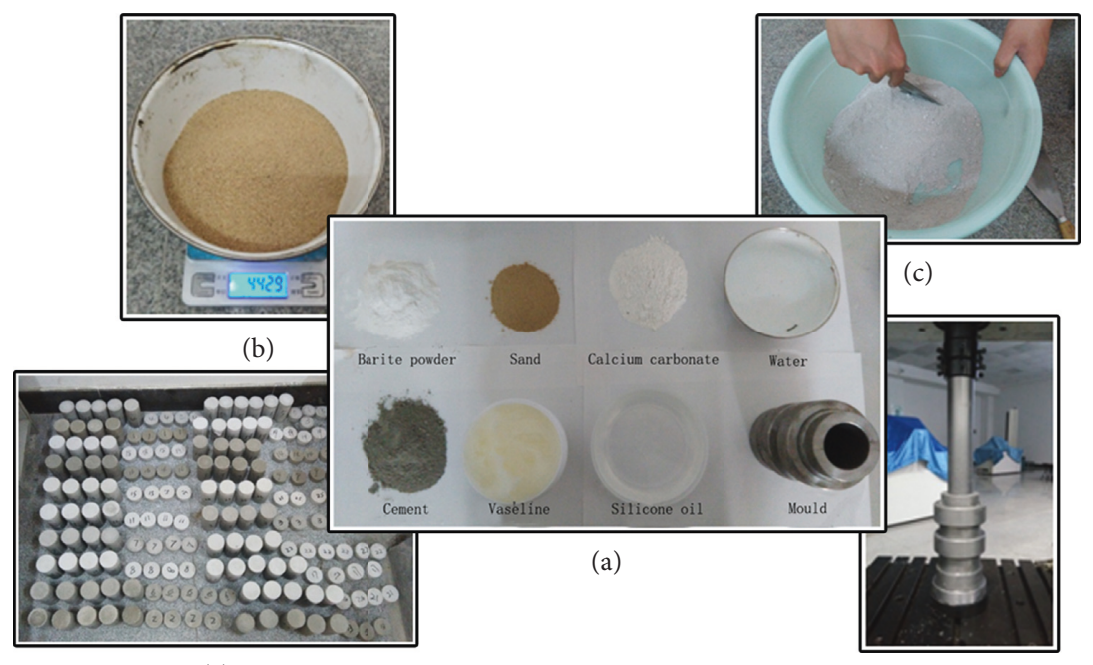

(e)

(f)

Figure 1: Original materials and production process. (a) Raw materials and mold. (b) Weighing. (c) Stirring. (d) Pressing molding. (e) Samples to be tested.

oil have a significant effect on the strength. In detail, strength is positively correlated with the cement-Vaseline ratio and negatively correlated with the ratio of silicone oil. Among them, different from tensile strength, there is a strong negative correlation with the barite ratio in compressive strength and elastic modulus. Moreover, the water absorption of similar materials is significantly negatively correlated with the silicone oil content.
Through the intuitive analysis of all factors and the relationship diagram, we can see that all the mechanical indexes of similar materials are mainly controlled by some of these factors and are mainly linear. In order to make the similar ratio more universal, we use the regression analysis method to link the orthogonal experiment factors with material mechanics properties and establish its linear regression relationship: 


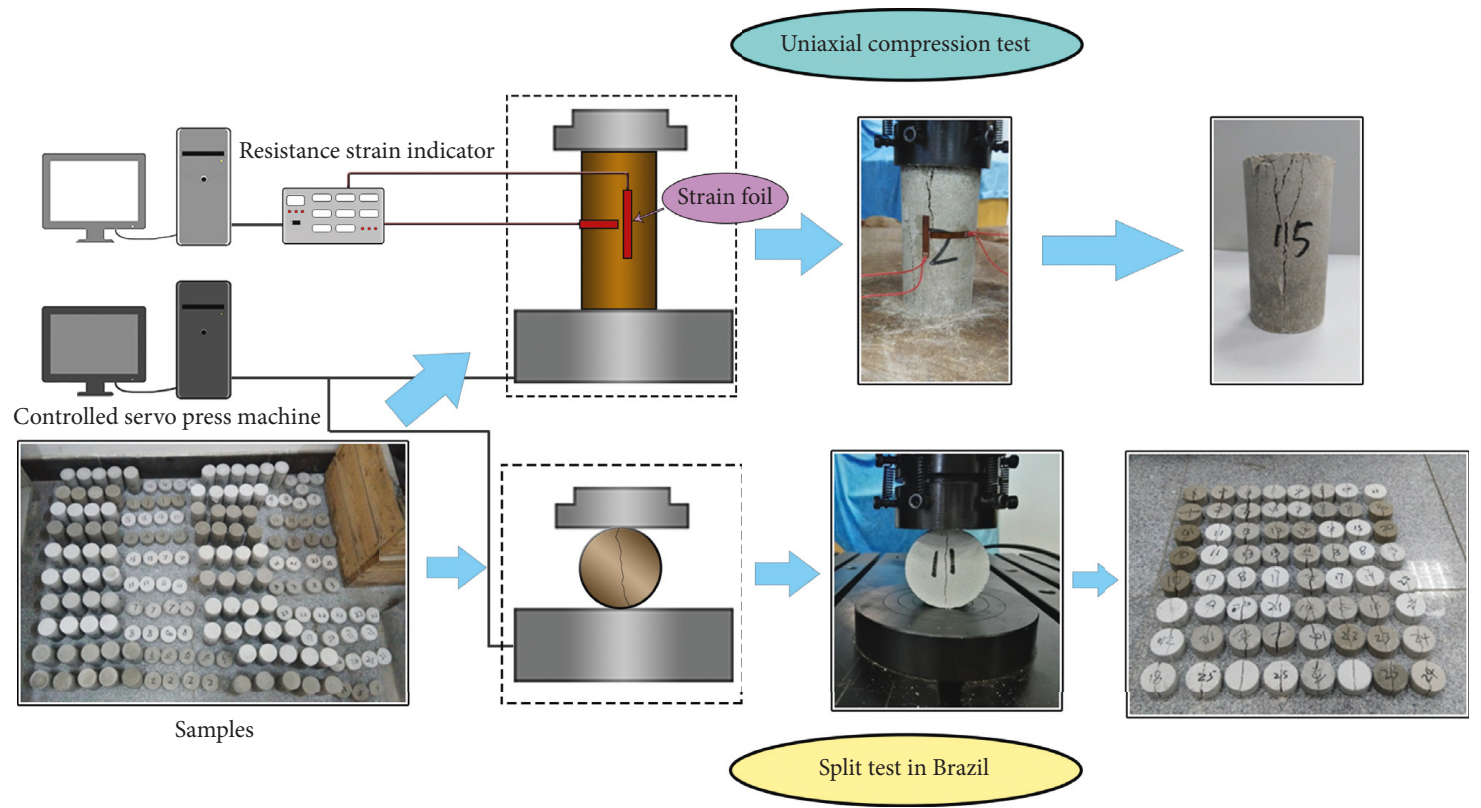

Figure 2: Tests about mechanical properties of specimens.

$$
\begin{aligned}
\left\{\begin{array}{c}
\rho \\
\mu \\
\sigma_{\mathrm{t}} \\
\sigma_{\mathrm{c}} \\
E_{\mathrm{e}} \\
W_{\mathrm{a}}
\end{array}\right\}= & \left(\begin{array}{ccccc}
-0.002 & -0.0031 & -0.0005 & -0.0011 & -0.0066 \\
-0.0043 & -0.0207 & 0.0022 & 0.001 & 0.0011 \\
-0.0057 & 0.0535 & -0.0007 & 0.0015 & -0.0147 \\
-0.1325 & 0.2945 & -0.0088 & -0.0032 & -0.0727 \\
-0.022 & 0.077 & -0.0019 & -0.0019 & -0.0077 \\
0.497 & 0.1653 & -0.0186 & -0.0122 & -1.09
\end{array}\right) \\
& \cdot\left\{\begin{array}{c}
\mathrm{A} \\
\mathrm{B} \\
\mathrm{C} \\
\mathrm{D} \\
\mathrm{E}
\end{array}\right\}+\left(\begin{array}{c}
1.843 \\
0.2137 \\
0.1367 \\
1.9082 \\
0.339 \\
10.2037
\end{array}\right),
\end{aligned}
$$

where, $\rho$ is density, $\mu$ is Poisson's ratio, $\sigma_{\mathrm{t}}$ is tensile strength, $\sigma_{\mathrm{c}}$ is compressive strength, $E_{\mathrm{e}}$ is elastic modulus, and $W_{\mathrm{a}}$ is water absorption rate. Also, $\mathrm{A}$ is aggregate-binder ratio, $\mathrm{B}$ is cement-Vaseline ratio, $\mathrm{C}$ is barite ratio, $\mathrm{D}$ is calcium carbonate ratio, and $\mathrm{E}$ is the ratio of silicone oil.

The aforementioned equation can calculate density, Poisson's ratio, tensile strength, compressive strength, elastic modulus, and water absorption rate of similar materials under the condition that the similar material matching scheme is known.

However, in practical engineering applications, it is often necessary to determine similar material ratios based on physical and mechanical parameters of materials that meet similar requirements. Since the density can be manually adjusted in the experiment, we do not use density as the main dependent variable. After removing density, we transform the equations to obtain a set of equations for calculating the material ratio from the mechanical parameters:

$$
\begin{aligned}
\left\{\begin{array}{l}
\mathrm{A} \\
\mathrm{B} \\
\mathrm{C} \\
\mathrm{D} \\
\mathrm{E}
\end{array}\right\}= & \left(\begin{array}{ccccc}
-18.7755 & 2.3155 & -5.368 & -1.4569 & 0.3806 \\
1.4275 & 1.7688 & -0.4293 & 2.6444 & 0.0352 \\
523.9259 & 3.4811 & -70.6372 & 380.7911 & 2.597 \\
-187.1133 & 37.9892 & 126.428 & -791.5744 & -2.517 \\
-15.1906 & 0.8394 & -2.7244 & 2.0987 & -0.7547
\end{array}\right) \\
& \cdot\left\{\begin{array}{c}
\mu \\
\sigma_{\mathrm{t}} \\
\sigma_{\mathrm{c}} \\
E_{\mathrm{e}} \\
W_{\mathrm{a}}
\end{array}\right\}+\left(\begin{array}{c}
10.5494 \\
-0.9833 \\
-133.2361 \\
87.5695 \\
15.3156
\end{array}\right) .
\end{aligned}
$$

In large-scale physics experiments related to hydrophilicity, the physical and mechanical parameters of similar materials that meet the requirements can be obtained by adjusting the aforementioned equation. Because these equations come from experimental fitting and are universal, therefore, equations (1) and (2) can be used as a reference for other related experiments.

\section{Instability Simulation of Overlying Strata with Hydrophilicity-Related Geomaterials}

3.1. Experimental Preparation. In order to make similar simulation results more accurate, we combine the specific geological parameters, use the aforementioned regression equation to simulate the actual model, use the simulated 
TABLE 2: Test results of mechanical properties.

\begin{tabular}{|c|c|c|c|c|c|c|}
\hline Number & $\begin{array}{l}\text { Density/ } \\
\mathrm{g} \cdot \mathrm{cm}^{-3}\end{array}$ & $\begin{array}{l}\text { Poisson's } \\
\text { ratio }\end{array}$ & $\begin{array}{l}\text { Tensile strength } \\
(\mathrm{MPa})\end{array}$ & $\begin{array}{c}\text { Compressive strength } \\
(\mathrm{MPa})\end{array}$ & $\begin{array}{l}\text { Modulus of elasticity } \\
\text { (GPa) }\end{array}$ & $\begin{array}{c}\text { Water absorption rate } \\
(\%)\end{array}$ \\
\hline 1 & 1.8206 & 0.123 & 0.3015 & 2.2450 & 0.4190 & 16.094 \\
\hline 2 & 1.7916 & 0.167 & 0.3704 & 2.6600 & 0.6080 & 7.839 \\
\hline 3 & 1.7666 & 0.211 & 0.0576 & 0.7800 & 0.4925 & 3.62 \\
\hline 4 & 1.7315 & 0.256 & 0.0262 & 0.2800 & 0.0505 & 1.244 \\
\hline 5 & 1.6397 & 0.287 & 0.0194 & 0.3050 & 0.0610 & 0.354 \\
\hline 6 & 1.7177 & 0.130 & 0.0604 & 1.2350 & 0.2240 & 2.286 \\
\hline 7 & 1.7182 & 0.361 & 0.1480 & 0.7700 & 0.2065 & 0.619 \\
\hline 8 & 1.7906 & 0.250 & 0.2823 & 1.2450 & 0.2915 & 14.052 \\
\hline 9 & 1.7992 & 0.254 & 0.0734 & 0.8150 & 0.1630 & 10.066 \\
\hline 10 & 1.7575 & 0.199 & 0.0196 & 0.3500 & 0.0555 & 8.752 \\
\hline 11 & 1.7778 & 0.169 & 0.4352 & 1.5950 & 0.4805 & 9.101 \\
\hline 12 & 1.7457 & 0.173 & 0.2038 & 1.5700 & 0.3400 & 5.891 \\
\hline 13 & 1.7462 & 0.217 & 0.0436 & 0.5650 & 0.0570 & 1.249 \\
\hline 14 & 1.7345 & 0.174 & 0.0199 & 0.3000 & 0.0400 & 0.926 \\
\hline 15 & 1.7615 & 0.237 & 0.1162 & 0.9650 & 0.1185 & 11.314 \\
\hline 16 & 1.6927 & 0.166 & 0.0405 & 0.7800 & 0.2460 & 1.874 \\
\hline 17 & 1.7763 & 0.241 & 0.2482 & 1.2350 & 0.2525 & 15.033 \\
\hline 18 & 1.7631 & 0.093 & 0.1536 & 1.2050 & 0.1845 & 10.947 \\
\hline 19 & 1.7330 & 0.243 & 0.1266 & 0.8050 & 0.1455 & 6.459 \\
\hline 20 & 1.7941 & 0.234 & 0.0377 & 0.3750 & 0.1055 & 3.634 \\
\hline 21 & 1.6912 & 0.204 & 0.2031 & 0.8400 & 0.2215 & 8.165 \\
\hline 22 & 1.7177 & 0.161 & 0.1804 & 0.9700 & 0.2170 & 5.162 \\
\hline 23 & 1.7381 & 0.166 & 0.0910 & 0.2650 & 0.4845 & 2.213 \\
\hline 24 & 1.7529 & 0.241 & 0.1124 & 0.6250 & 0.1240 & 13.157 \\
\hline 25 & 1.8130 & 0.273 & 0.0341 & 0.2650 & 0.0365 & 11.794 \\
\hline
\end{tabular}

ratio to build a similar model, and carry out the mining experiment, vertical stress, and failure mode observation.

The experimental model of the rock stratum model was taken from the overlying strata between the water-separated layer and the coal seam in the Cuimu mining area in northwestern China, with a simulated buried depth of about $350 \mathrm{~m}$ to $500 \mathrm{~m}$. Taking a main mining face of the mine as an example, there is no large fault structure in the mining area, and the roof is managed by long-wall caving, coal mining, and slumping. The geometric similarity ratio between the prototype and the model is $200: 1$, the density similarity ratio is $1.3: 1$, and the stress similarity ratio is $260: 1$. From the similar ratio, we can calculate the material ratio. For some ratios that are negative, we set the ratio to 0 . The model size is $140 \mathrm{~cm} \times 110 \mathrm{~cm} \times 10 \mathrm{~cm}$. The initial vertical ground stress is supplemented by laying heavy weights on top of the model. Geological parameters and similar materials ratio are shown in Tables 4 and 5 .

In addition, 8 measuring points are arranged in the model to monitor changes of the internal vertical stress with zero initial stress. These points are placed in the $6^{\text {th }}$ layer of sandy mudstone and the $10^{\text {th }}$ and $11^{\text {th }}$ layers of coarse sandstone. Four displacement sensors are placed on the top of the model to monitor the top subsidence of the model. Certainly, for surface displacement, we placed a $10 \mathrm{~cm} \times 10 \mathrm{~cm}$ grid on the surface of the model for observation. The experimental overall test system and the distribution of measuring points are shown in Figures 4 and 5.
3.2. Experimental Results and Analysis. Similar model total design mining is performed 11 times. Total mining length is $110 \mathrm{~cm}$ (prototype $220 \mathrm{~m}$ ). $15 \mathrm{~cm}$ (prototype $30 \mathrm{~m}$ ) coal pillars are reserved at both ends of the model to eliminate the effect of boundary effects. In order to reduce the influence of mining speed on formation/deformation, the mining speed is set to $10 \mathrm{~cm} / \mathrm{d}$ (prototype $20 \mathrm{~m} / \mathrm{d}$ ). The stress curve of the measuring point is shown in Figure 6.

At the beginning of mining, stress at the measuring point gradually increased, and the $1 \#$ and $4 \#$ measuring points closest to the advancing surface increased most obviously and reached a maximum value of about $1.1 \mathrm{MPa}$ at $40 \mathrm{~m}$. At this point, the rock formation is in an undamaged phase as a whole. The $40 \mathrm{~m}-120 \mathrm{~m}$ propulsion process is the stage of damage development. The overburden rock begins to rupture and the overall stress changes more and more intense. The $1 \#$ measuring point began to destabilize after the working surface was advanced to $80 \mathrm{~m}$, and its stress quickly dropped to $-10.18 \mathrm{MPa}$. After advancing to $120 \mathrm{~m}$, the overlying rock enters the complete destruction stage. The 2\# measurement position gradually begins to break. The stress at the measuring point is released quickly. At this time, the working surface advancement position is exactly $120 \mathrm{~m}$, and the maximum stress reaches $-10.21 \mathrm{MPa}$. After that, the position of the $3 \#$ measuring point is also destroyed after the working surface is advanced to $160 \mathrm{~m}$. During the experiment, the maximum stress after release is approximately equal to its original rock stress. In this process, 

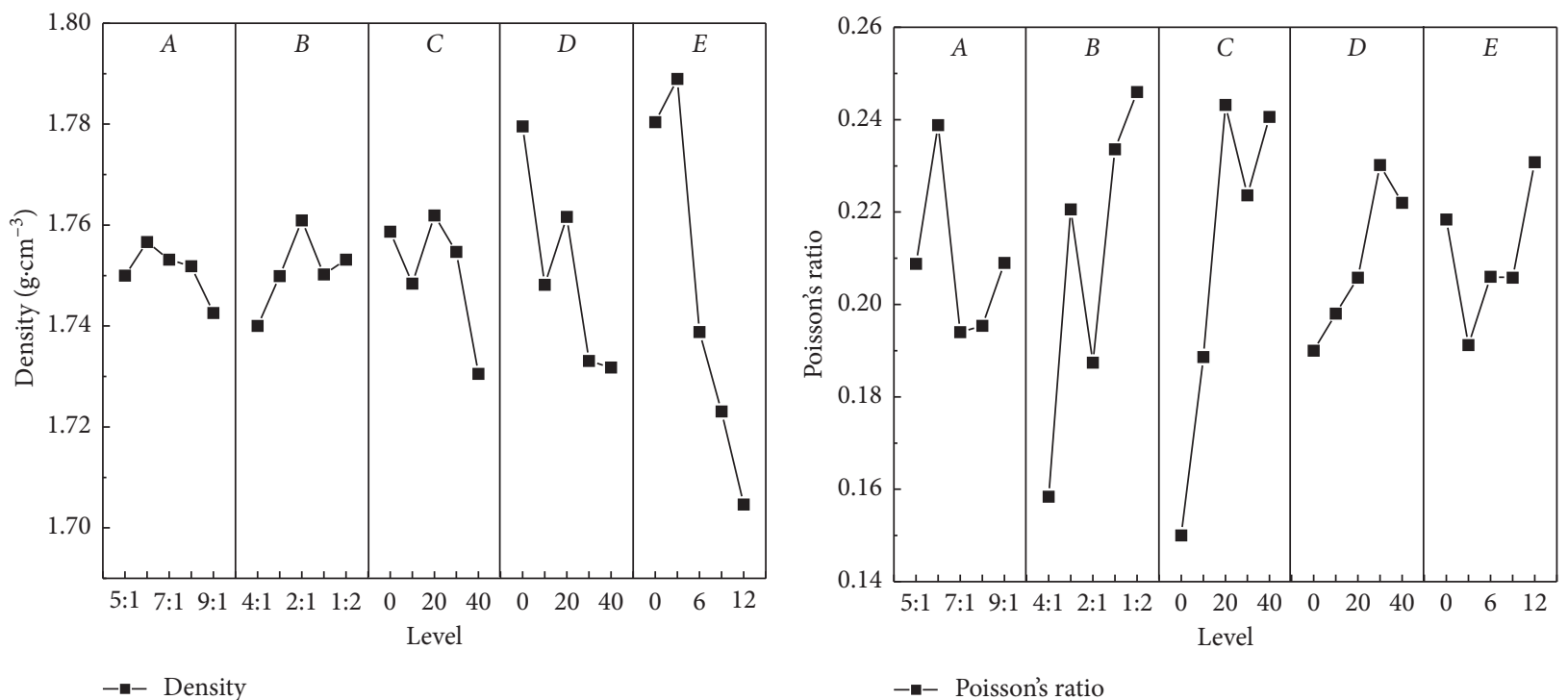

(a)
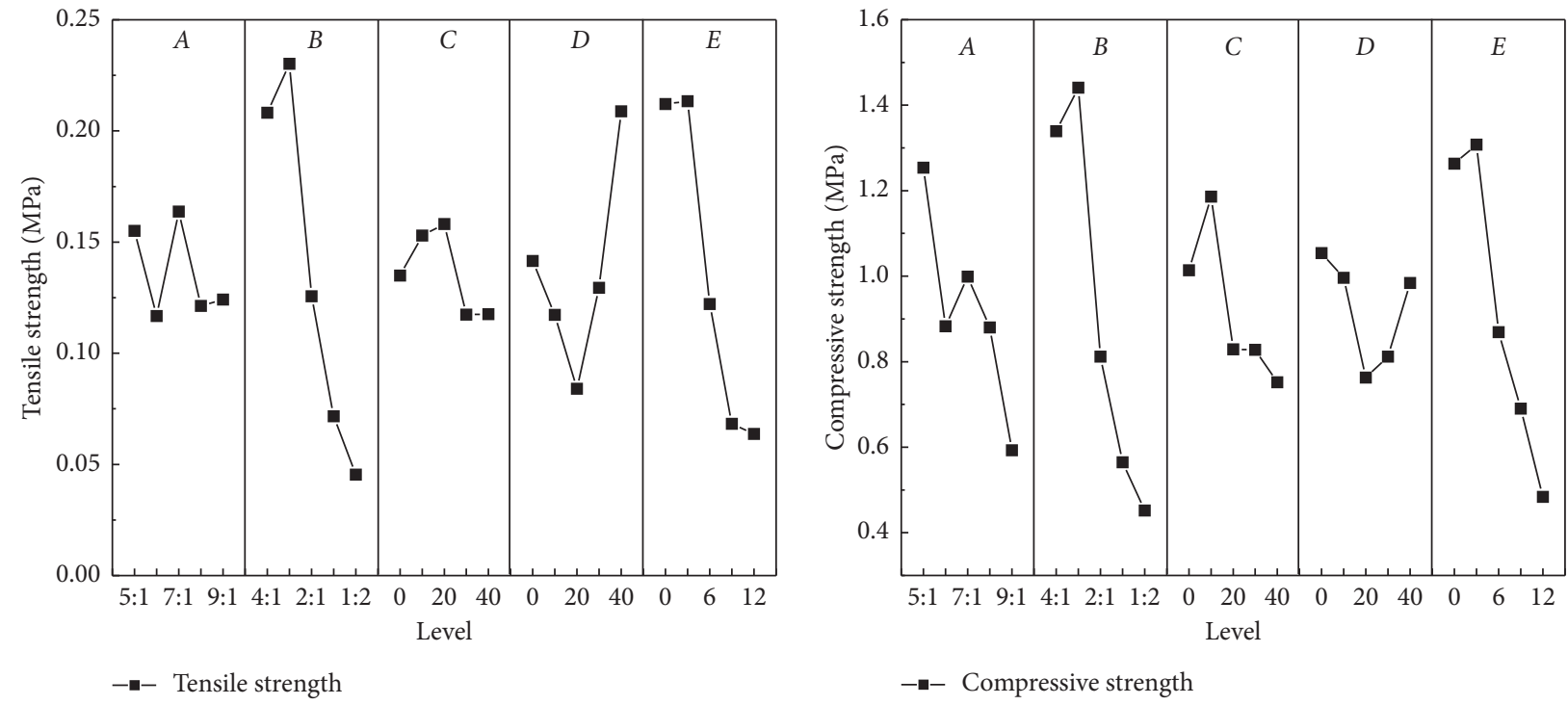

(c)

(d)
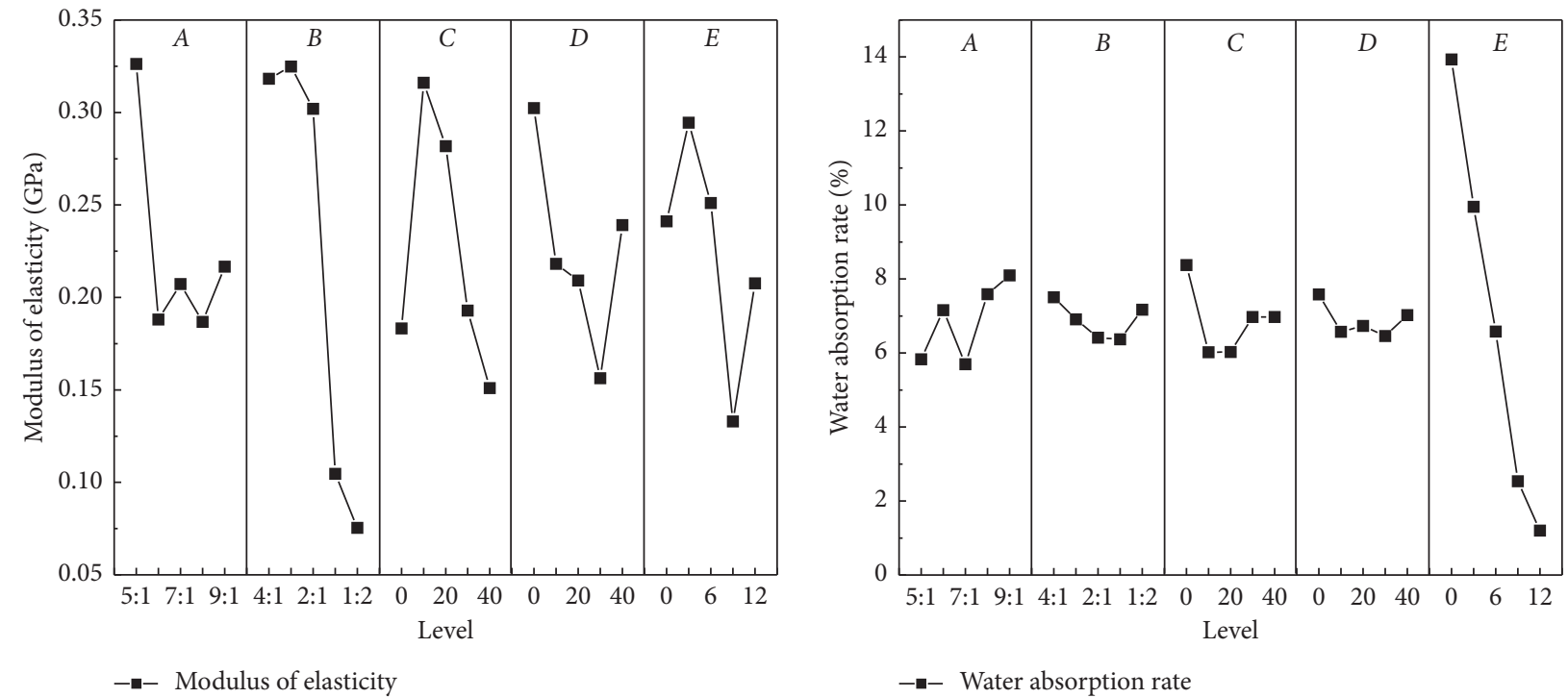

(e)

(f)

Figure 3: Effect of factors on: (a) density, (b) Poisson's ratio, (c) tensile strength, (d) compressive strength, (e) modulus of elasticity, and (f) water absorption rate. 
TABLE 3: Spearman correlation coefficient.

\begin{tabular}{lcccccc}
\hline Level & $\begin{array}{c}\text { Density/ } \\
\text { g.cm }\end{array}$ & $\begin{array}{c}\text { Poisson's } \\
\text { ratio }\end{array}$ & Tensile strength (MPa) & $\begin{array}{c}\text { Compressive } \\
\text { strength (MPa) }\end{array}$ & $\begin{array}{c}\text { Modulus of elasticity (GPa) } \\
\text { eler }\end{array}$ & $\begin{array}{c}\text { Water absorption } \\
\text { rate (\%) }\end{array}$ \\
\hline (A) Aggregate-binder ratio & -0.1393 & -0.1334 & 0.0667 & -0.1982 & -0.1294 & 0.2 \\
(B) Cement-Vaseline ratio & -0.1746 & -0.5650 & 0.6472 & 0.6495 & 0.7256 & 0.0353 \\
(C) Barite ratio & -0.0726 & 0.5886 & -0.0902 & -0.1217 & -0.0706 & -0.0706 \\
(D) Calcium carbonate ratio & -0.3688 & 0.2590 & 0.1334 & 0.0922 & -0.1216 & -0.0667 \\
(E) Content of silicone oil & -0.6944 & -0.0314 & -0.5648 & -0.5573 & -0.2118 & -0.9453 \\
\hline
\end{tabular}

TABLE 4: Overlying strata structure of working face.

\begin{tabular}{|c|c|c|c|c|c|c|c|c|}
\hline Number & Rock stratum & $\begin{array}{l}\text { Thickness } \\
\text { (m) }\end{array}$ & $\begin{array}{l}\text { Volume } \\
\text { Weight } \\
\left(\mathrm{g} / \mathrm{cm}^{3}\right)\end{array}$ & $\begin{array}{c}\text { Compressive } \\
\text { strength } \\
(\mathrm{MPa})\end{array}$ & $\begin{array}{c}\text { Tensile } \\
\text { strength } \\
(\mathrm{MPa})\end{array}$ & $\begin{array}{c}\text { Elastic } \\
\text { modulus } \\
(\mathrm{GPa})\end{array}$ & $\begin{array}{l}\text { Poisson's } \\
\text { ratio }\end{array}$ & $\begin{array}{c}\text { Water absorption } \\
\text { rate }\end{array}$ \\
\hline 11 & Coarse sandstone & 73.7 & $2.3-2.52$ & 117.5 & 14.90 & 21.30 & 0.27 & 2 \\
\hline 10 & Coarse sandstone & 48 & $2.3-2.52$ & 146.2 & 7.70 & 15.50 & 0.23 & 2 \\
\hline 9 & $\begin{array}{l}\text { Medium-grained } \\
\text { sandstone }\end{array}$ & 6 & $2.4-2.48$ & 53.7 & 1.70 & 7.94 & 0.22 & 12 \\
\hline 8 & Sandy mudstone & 7.4 & $2.27-2.44$ & 30.3 & 1.25 & 3.34 & 0.21 & 6 \\
\hline 7 & Sandy mudstone & 38.9 & $2.27-2.44$ & 121.3 & 5 & 5.4 & 0.25 & 6 \\
\hline 6 & Mudstone & 8.7 & $2.18-2.34$ & 38.8 & 1.2 & 1.2 & 0.15 & 0.7 \\
\hline 5 & Coarse sandstone & 7.3 & $2.3-2.52$ & 24.3 & 1 & 5.5 & 0.22 & 2 \\
\hline 4 & Mudstone & 6.9 & $2.18-2.34$ & 21.5 & 0.9 & 3.34 & 0.2 & 0.7 \\
\hline 3 & Sandy mudstone & 9.6 & $2.27-2.44$ & 49 & 3.6 & 9.5 & 0.19 & 6 \\
\hline 2 & Coarse sandstone & 4 & $2.3-2.52$ & 25.6 & 1 & 3.94 & 0.23 & 2 \\
\hline 1 & Coal & 16 & $1.4-1.66$ & 10.2 & 0.64 & 1.49 & 0.31 & 10 \\
\hline
\end{tabular}

TABle 5: Similar material ratio of each rock layer.

\begin{tabular}{|c|c|c|c|c|c|c|}
\hline Number & Rock stratum & A & $\mathrm{B}$ & $\mathrm{C}$ & $\mathrm{D}$ & $E$ \\
\hline 11 & Coarse sandstone & 3.83 & -0.40 & 12.89 & 26.48 & 8.69 \\
\hline 10 & Coarse sandstone & 3.96 & -0.62 & -24.45 & 64.53 & 8.93 \\
\hline 9 & Medium-grained sandstone & 9.85 & -0.24 & 10.25 & 18.39 & 2.42 \\
\hline 8 & Sandy mudstone & 8.26 & -0.48 & -10.95 & 37.92 & 7.31 \\
\hline 7 & Sandy mudstone & 5.65 & -0.53 & -11.65 & 68.96 & 5.78 \\
\hline 6 & Mudstone & 7.20 & -0.79 & -61.60 & 73.13 & 12.12 \\
\hline 5 & Coarse sandstone & 6.66 & -0.58 & -11.31 & 36.59 & 10.26 \\
\hline 4 & Mudstone & 6.61 & -0.67 & -27.57 & 48.80 & 11.55 \\
\hline 3 & Sandy mudstone & 8.23 & -0.46 & -17.46 & 32.35 & 7.48 \\
\hline 2 & Coarse sandstone & 6.45 & -0.58 & -8.71 & 40.10 & 10.08 \\
\hline 1 & Coal & 8.32 & -0.19 & 54.57 & 4.91 & 2.97 \\
\hline
\end{tabular}

although the rock layers of $4 \#, 5 \#$, and $6 \#$ measuring points are damaged, the internal stress variation laws are similar to those of $1 \#, 2 \#$, and $3 \#$ measuring points. There is no obvious stress change in $7 \#$ and $8 \#$ measuring points, indicating that the mining has little effect on this layer. The displacement of the surface of the similar model presents a "funnel shape"(Figure 7), which is similar to engineering. The surface displacement increment gradually increases from the boundary to the middle. After the completion of the mining, the displacement at the boundary changes minimally, about $0.57 \mathrm{~m}$. The central displacement changes by about $1.35 \mathrm{~m}$, which is the maximum change position.

The destruction process of the overlying rock in the mine during the progress of the work surface is shown in Figure 8 .

It can be seen that the direct roof of the mined area is periodically and orderly broken along with the advancement of the working face, and the height of the overlying rock formation is gradually increased. Above the working face, the overburden acts directly on the top of the stope frame with a combined cantilever structure.

The bottom surface of the $10^{\text {th }}$ layer of the coarse sandstone layer is about $85 \mathrm{~m}$ away from the top surface of the coal seam. The overburden strata on the working surface fell below the $10^{\text {th }}$ layer of coarse sandstone and formed a clear separation space. The coarse sandstone layer as the main bearing layer also undergoes slight bending deformation. In the meantime, the cross-layer fracture occurred in the $11^{\text {th }}$ layer. As we all know, the fracture behavior of rocks depends on the microstructures of the rocks: the distribution and orientation of the microcracks and the type, size, and shape of mineral grains [22]. The main reason is that the $10^{\text {th }}$ layer is bent and sinks to create a separation space. In turn, the lower portion of the $11^{\text {th }}$ layer is fractured by tensile stress. 


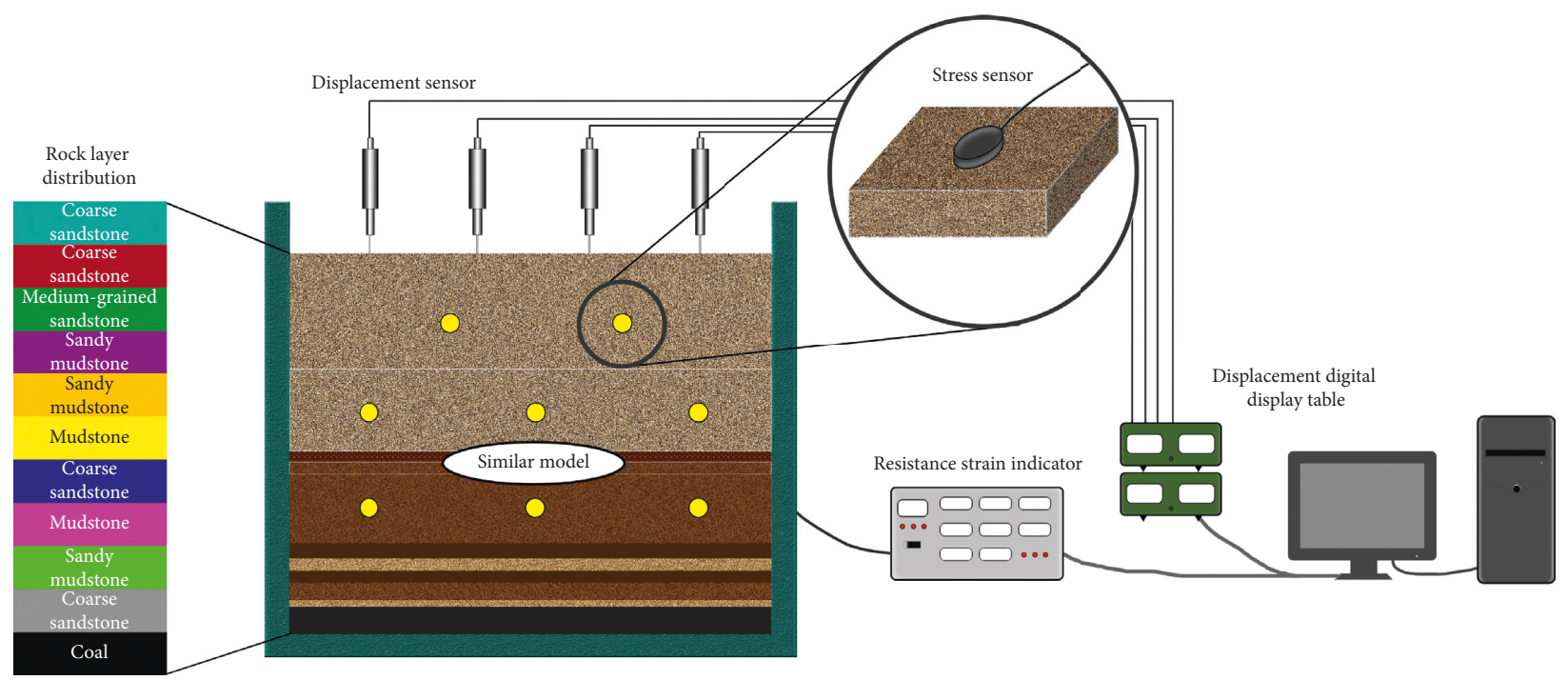

Figure 4: Similar model experiment test system.

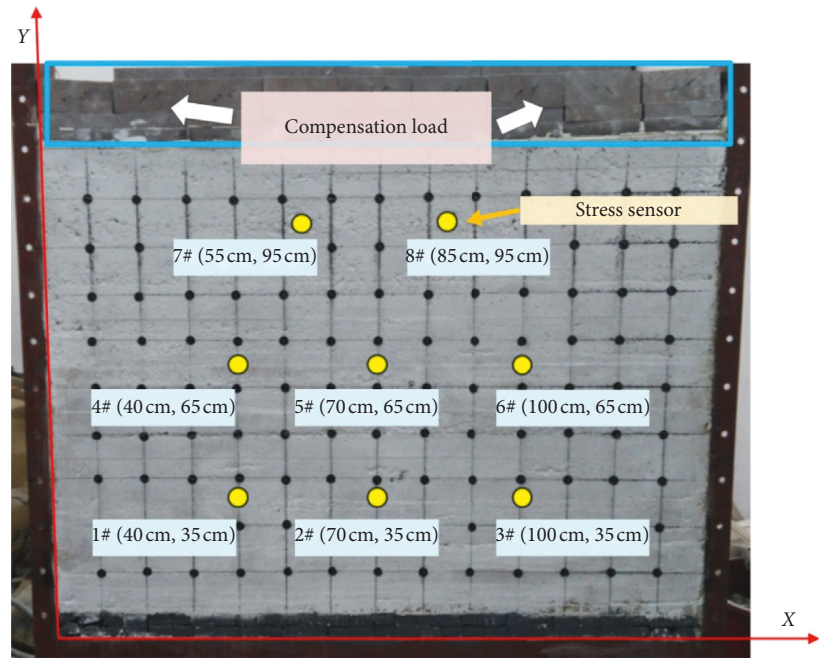

FIGURE 5: Distribution of measuring points.

At the end of mining, there is a clear collapse zone, a water-guiding fissure zone, and a separation space in the overlying strata, which are consistent with the engineering practice. The height of the collapse zone is about $72 \mathrm{~m}$, and the maximum height of the water-guiding fissure zone is about $160 \mathrm{~m}$.

According to the data of drilling exploration in the field, the distance between the coal seam and aquifer, the height of the collapse zone, and the height of the water-guiding fissure zone are shown in Table 6. Comparing with the field data, it can be found that the height of the collapse zone and waterguiding fissure zone measured at three boreholes are in good agreement with the experiment.

In the experiment of applying self-developing hydrophilicity-related materials to the engineering, the materials are consistent with the actual engineering in simulating the stress, displacement state and failure mode of hydrophilicity. The similar materials developed in this paper not only consider the hydrophilicity but also verify its high accuracy in the laboratory-engineering simulation scale. Therefore, the experiment in this paper is successful. Although for technical reasons, this paper does not add water to similar experiments in the simulation project, but it has made a pioneering contribution to the experiment of the influence of water on overburden under simulated mining conditions.

\section{Conclusions}

In this paper, by employing the orthogonal testing method, we got the ingredient ratios of similar hydrophilicity-related materials and built the corresponding physical model. Then, the mechanical properties of materials were tested, and the failure progress of the workface in a coal mine of Northwest China was simulated. The main conclusions are as follows:

(1) To prepare a hydrophilicity-related material that meets the requirements of a laboratory physical simulation test with similar materials, similar materials mixed from sand, cement, barite, calcium 


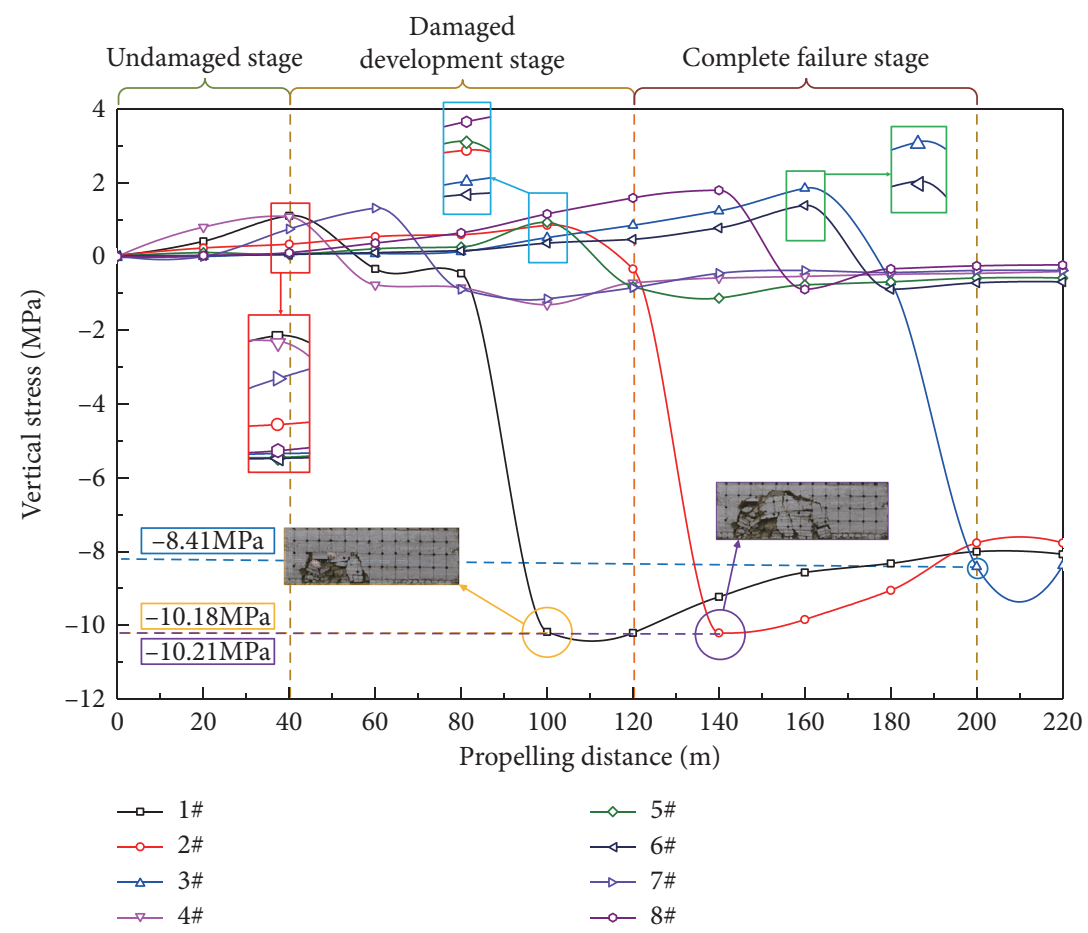

FIGURE 6: Stress curve of the measuring point.

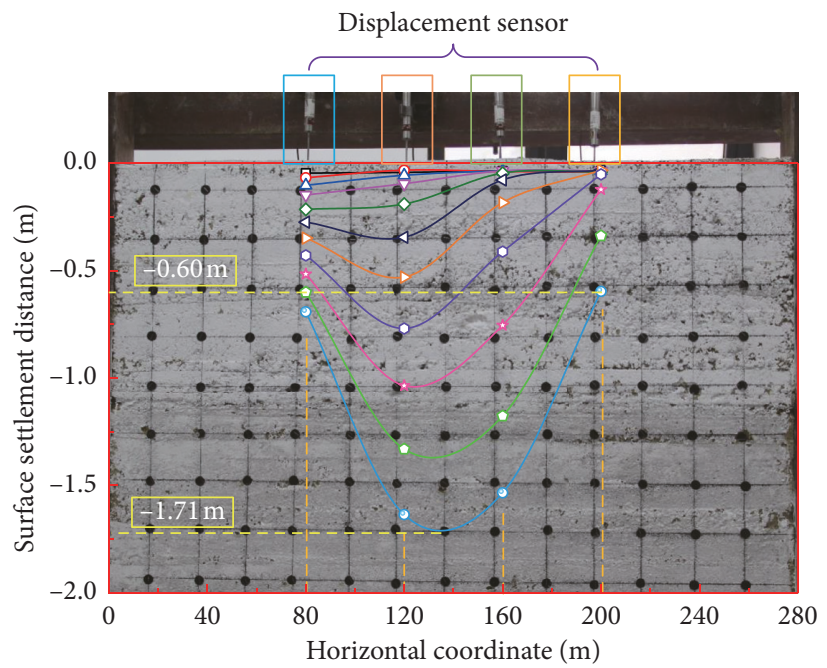

Propelling distance

$$
\begin{array}{llll}
\neg 20 \mathrm{~m} & \rightarrow 80 \mathrm{~m} & \rightarrow 140 \mathrm{~m} & \multimap-200 \mathrm{~m} \\
\multimap 40 \mathrm{~m} & \multimap 100 \mathrm{~m} & \rightarrow 160 \mathrm{~m} & \rightarrow 220 \mathrm{~m} \\
\triangle 60 \mathrm{~m} & \neg 120 \mathrm{~m} & \rightarrow-180 \mathrm{~m} &
\end{array}
$$

Figure 7: Model of vertical displacement on the surface of the model.

carbonate, Vaseline, and silicone oil are researched in an orthogonal study. The sample density is about $1.6397-1.8206 \mathrm{~g} / \mathrm{cm}^{3}$, Poisson's ratio is between 0.093 and 0.361 , tensile strength is between $0.0194 \mathrm{MPa}$ and $0.1352 \mathrm{MPa}$, uniaxial compressive strength is between $0.2650 \mathrm{MPa}$ and $2.6600 \mathrm{MPa}$, the elastic modulus is about $0.0365 \mathrm{GPa}-0.6080 \mathrm{GPa}$, and the water absorption rate is between $0.354 \%$ and $16.094 \%$. Therefore, the values of mechanical properties and hydrophilicity of similar materials meet the requirements of most laboratory physical simulation tests.

(2) Silicone oil content is the main factor affecting density and water absorption and is negatively correlated with a linear relationship. The cement-Vaseline ratio mainly affects the mechanical properties of similar materials, namely, Poisson's ratio, tensile strength, 

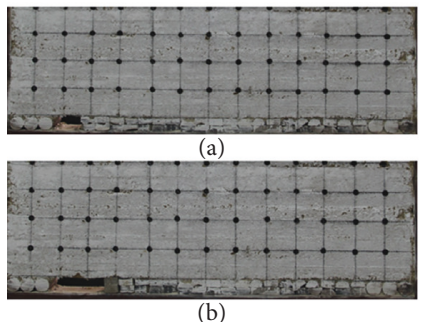

(b)

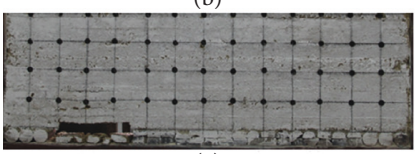

(c)

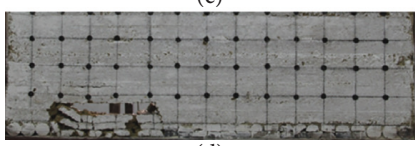

(d)
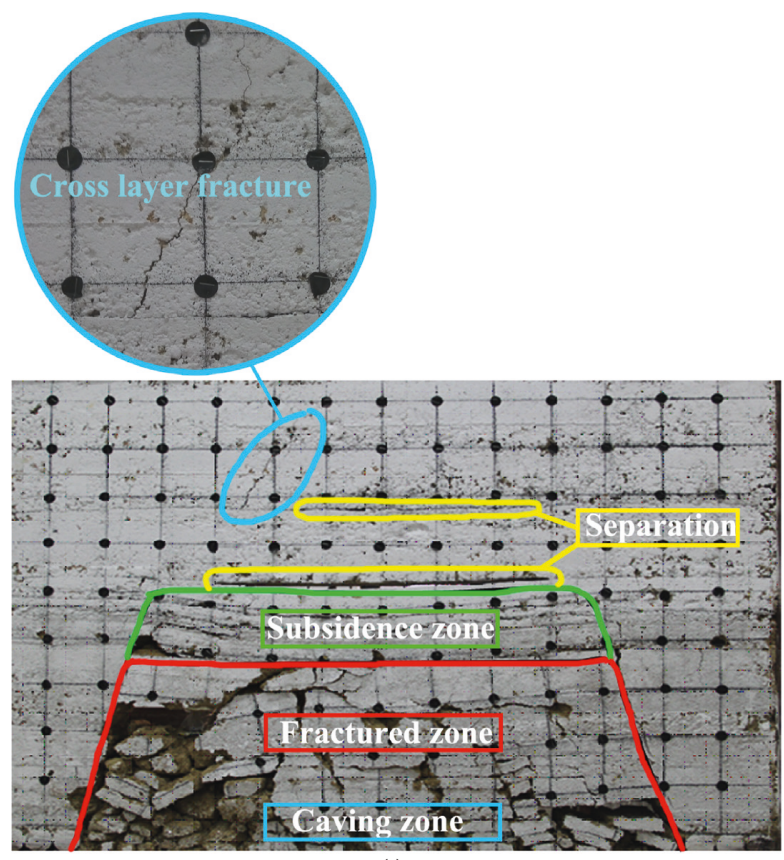

(i)

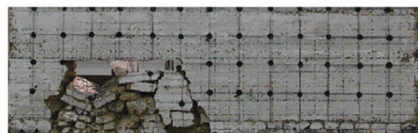

(e)

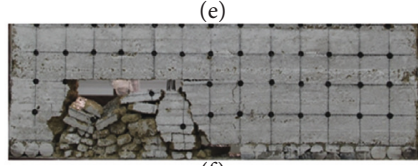

(f)

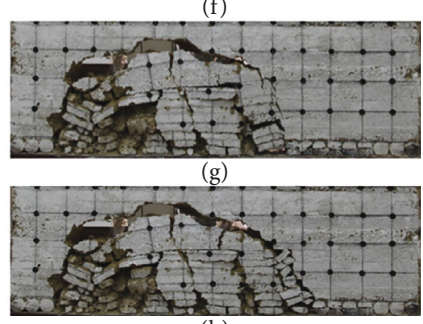

(h)

Figure 8: Failure process diagram of the overlying strata. Face advancing (a) $20 \mathrm{~m}$, (b) $40 \mathrm{~m}$, (c) $60 \mathrm{~m}$, (d) $80 \mathrm{~m}$, (e) $100 \mathrm{~m}$, (f) $120 \mathrm{~m}$, (g) $140 \mathrm{~m}$, (h) $160 \mathrm{~m}$, and (i) $220 \mathrm{~m}$.

TABLE 6: On-site borehole survey data of working face.

\begin{tabular}{lccccc}
\hline Drilling number & $\begin{array}{c}\text { Distance from coal } \\
\text { seam to aquifer }\end{array}$ & $\begin{array}{c}\text { Coal seam } \\
\text { thickness }\end{array}$ & $\begin{array}{c}\text { Caving zone } \\
\text { height }(\mathrm{m})\end{array}$ & $\begin{array}{c}\text { Height of the water-guiding } \\
\text { fissure zone }\end{array}$ & $\begin{array}{c}\text { Thickness of } \\
\text { protective layer }\end{array}$ \\
\hline K6-3 & 304.04 & 16.15 & 64.4 & 160.39 & 4.03 \\
X7-2 & 322.05 & 17.89 & 71.56 & 177.12 & 10.13 \\
X7-3 & 298.58 & 9.5 & 38 & 96.45 & 52.39 \\
\hline
\end{tabular}

compressive strength, and modulus of elasticity, and the cement-Vaseline ratio is negatively correlated with these mechanical properties. The aggregate-binder ratio, barite ratio, and calcium carbonate ratio have a certain effect on the material properties, but they are not the dominant factors. Through the sensitivity analysis of the material properties and ratio, the correlation coefficient table of mechanical properties and material ratio is obtained, and the correlation equation of the mechanical properties of the materials is calculated by using five factors.

(3) Based on the orthogonal experimental results and the actual geological parameters, an experimental model of similar materials of overburden under the influence of mining was established under the condition of considering the hydrophilicity of the formation. During the mining process, due to the failure of overburden, the maximum stress release measured by the stress sensor is approximately the original rock stress. The ground surface settlement measured by the displacement sensor is "funnel shape." After the mining is completed, the overburden structure presents an obvious "three-band" structure. The failure mode of overburden and the vertical stress and displacement changes are consistent with actual engineering. Although water has not been added to physical experiments, it provides the basis for future research on large-scale physical water-containing experiments.

\section{Data Availability}

The data used to support the findings of this study are available from the corresponding author upon request.

\section{Conflicts of Interest}

The authors declare that they have no conflicts of interest.

\section{Acknowledgments}

This study was supported by a special subject grant of the National "973" Basic Research Program of China (no. 2015CB251602), National Science and Technology Major (2016ZX05043), Jiangsu Natural Science Foundation (BK20180636), the Independent Innovation Project for Double First-level Construction of CUMT (2018ZZCX04), Opening Fund (no. 2016A01), and China and Jiangsu Planned Projects for Postdoctoral Research Funds. The 
authors are grateful to all the help from mentor and teammates for experiments and theories.

\section{References}

[1] M. Bassani, F. Bertola, M. Bianchi, F. Canonico, and M. Marian, "Environmental assessment and geomechanical properties of controlled low-strength materials with recycled and alternative components for cements and aggregates," Cement and Concrete Composites, vol. 80, pp. 143-156, 2017.

[2] J. Chai, W. Du, Q. Yuan, and D. Zhang, "Analysis of test method for physical model test of mining based on optical fiber sensing technology detection," Optical Fiber Technology, vol. 48, pp. 84-94, 2019.

[3] S. Chen, H. Wang, J. Zhang, H. Xing, and H. Wang, "Lowstrength similar materials for backfill mining: insight from experiments on components and influence mechanism," Geotechnical Testing Journal, vol. 38, no. 6, Article ID 20140103, 2015.

[4] W.-P. Fei, L. Zhang, and R. Zhang, "Experimental study on a geo-mechanical model of a high arch dam," International Journal of Rock Mechanics and Mining Sciences, vol. 47, no. 2, pp. 299-306, 2010.

[5] F. Luo, B. S. Yang, B. B. Hao, L. H. Sun, and F. U. Ming-Ming, "Mechanical properties of similar material under uniaxial compression and the strength error sources," Journal of Mining \& Safety Engineering, vol. 30, no. 1, pp. 93-99, 2013.

[6] M. A. Meguid, O. Saada, M. A. Nunes, and J. Mattar, "Physical modeling of tunnels in soft ground: a review," Tunnelling and Underground Space Technology, vol. 23, no. 2, pp. 185-198, 2008.

[7] X. Wang, X. Liu, E. Wang et al., "Experimental research of the $\mathrm{AE}$ responses and fracture evolution characteristics for sandparaffin similar material," Construction and Building Materials, vol. 132, pp. 446-456, 2017.

[8] L. Xu, W. M. Ye, B. Ye, B. Chen, Y. G. Chen, and Y. J. Cui, "Investigation on gas migration in saturated materials with low permeability," Engineering Geology, vol. 197, pp. 94-102, 2015.

[9] H. Yasuhara, N. Kinoshita, D. S. Lee, J. Choi, and K. Kishida, "Evolution of mechanical and hydraulic properties in sandstone induced by simulated mineral trapping of $\mathrm{CO}_{2}$ geosequestration," International Journal of Greenhouse Gas Control, vol. 56, pp. 155-164, 2017.

[10] Q.-Y. Zhang, Y. Zhang, K. Duan, C.-C. Liu, Y.-S. Miao, and $\mathrm{D}$. $\mathrm{Wu}$, "Large-scale geo-mechanical model tests for the stability assessment of deep underground complex under true-triaxial stress," Tunnelling and Underground Space Technology, vol. 83, pp. 577-591, 2019.

[11] D.-Z. Gu, "Technology development and engineering practice for protection and utilization of water resources in coal mining in western China," Frontiers of Engineering Management, vol. 3, no. 1, p. 59, 2016.

[12] Z. Q. Hu, Y. L. Zhao, and Y. G. Gao, "Impact of coal resource development on eco-environment and its restoration in west of China," Transactions of Nonferrous Metals Society of China, vol. 15, no. S1, pp. 168-171, 2005.

[13] K. Wang, S. C. Li, Q. S. Zhang et al., "Development and application of new similar materials of surrounding rock for a fluid-solid coupling model test," Rock \& Soil Mechanics, vol. 37, no. 9, pp. 2521-2533, 2016.

[14] X. S. Liu, Y. L. Tan, J. G. Ning, Y. W. Lu, and Q. H. Gu, "Mechanical properties and damage constitutive model of coal in coal-rock combined body," International Journal of
Rock Mechanics and Mining Sciences, vol. 110, pp. 140-150, 2018.

[15] C. Oggeri, T. M. Fenoglio, A. Godio, and R. Vinai, "Overburden management in open pits: options and limits in large limestone quarries," International Journal of Mining Science and Technology, vol. 29, no. 2, pp. 217-228, 2019.

[16] L.-J. Su, J.-H. Yin, and W.-H. Zhou, "Influences of overburden pressure and soil dilation on soil nail pull-out resistance," Computers and Geotechnics, vol. 37, no. 4, pp. 555-564, 2010.

[17] A. M. Suchowerska Iwanec, J. P. Carter, and J. P. Hambleton, "Geomechanics of subsidence above single and multi-seam coal mining," Journal of Rock Mechanics and Geotechnical Engineering, vol. 8, no. 3, pp. 304-313, 2016.

[18] G. Yu, W. Mi, D. Wang, L. Gao, S. Lu, and G. Li, "Research on the relationship between the surface dynamic subsidence and overburden separated strata of coal mine and its model," Procedia Engineering, vol. 191, pp. 196-205, 2017.

[19] J. Zhang, Q. Zhang, A. J. S. Spearing, X. Miao, S. Guo, and Q. Sun, "Green coal mining technique integrating miningdressing-gas draining-backfilling-mining," International Journal of Mining Science and Technology, vol. 27, no. 1, pp. 17-27, 2017.

[20] B. Guo, T. Cheng, L. Wang, T. Luo, and X. Yang, "Physical simulation of water inrush through the mine floor from a confined aquifer," Mine Water and the Environment, vol. 37, no. 3, pp. 577-585, 2018.

[21] K. Wu, G.-L. Cheng, and D.-W. Zhou, "Experimental research on dynamic movement in strata overlying coal mines using similar material modeling," Arabian Journal of Geosciences, vol. 8, no. 9, pp. 6521-6534, 2015.

[22] M. Kataoka, S.-S. Jeong, Y. Obara, T. Yoshinaga, Y. Mine, and K. Takashima, "Testing method for determination of microscopic fracture toughness for rock materials," Geotechnical Testing Journal, vol. 41, no. 6, Article ID 20170183, 2018. 


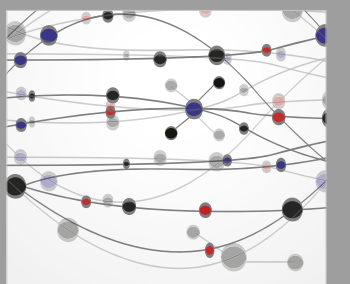

The Scientific World Journal
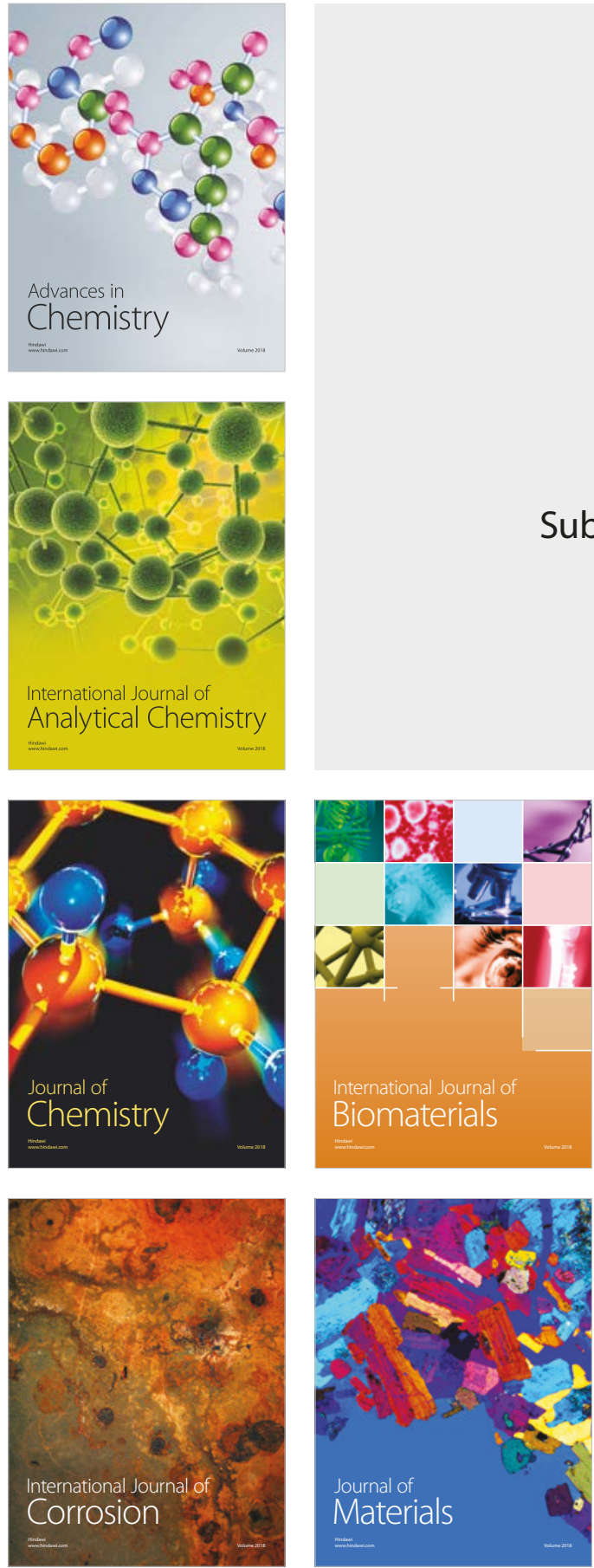

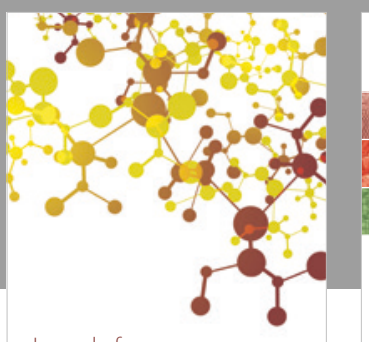

Journal of

Applied Chemistry
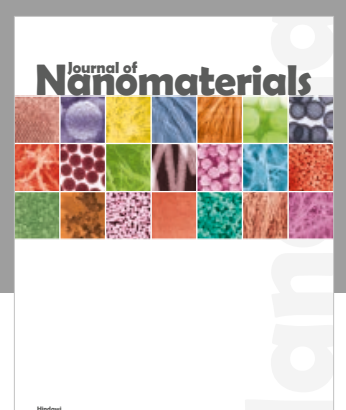

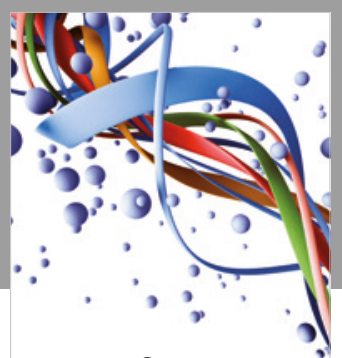

Scientifica

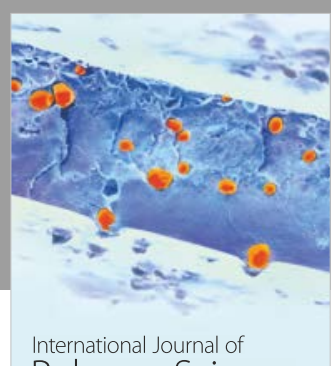

Polymer Science

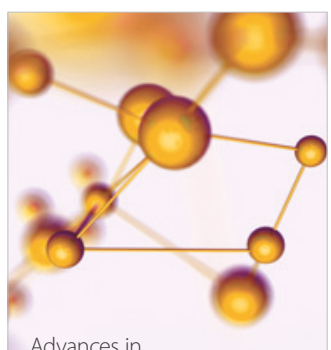

Physical Chemistry
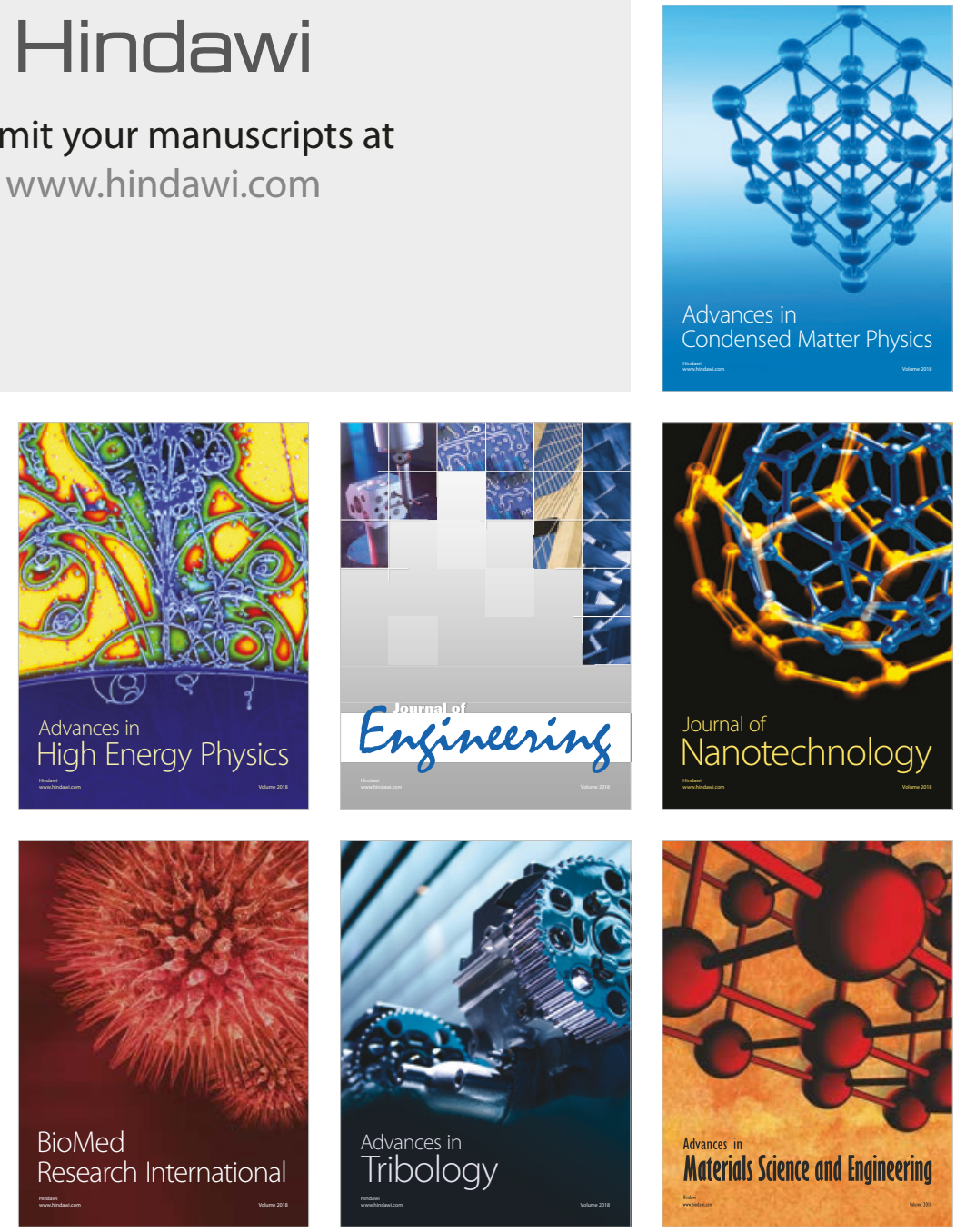